\title{
LETTERS
}

\section{Holistic First Nations health strategy: Canada}

I would like to thank the authors of the commentary "Canada needs a holistic First Nations health strategy" for their thoughtful article. ${ }^{1}$ I agree with their approach. However, given the complexity of delivering quality health care in Canada, I think that First Nations will need considerable assistance and support to achieve the required capacity to deliver a high-quality health care system to their many different communities. This will take time. A lot of time.

Second, if history has taught us anything, it is obvious that the federal government has been unable to deploy the necessary resources to provide the required support, despite trying to do so for more than a century.
Health care in Canada is largely delivered through provincial health care systems to the rest of the population. Why have First Nations been left out? Should they not have the same access to provincial systems (e.g., health and education) as the rest of Canadians? There is an urgent need for boots on the ground (physicians, nurses, addiction workers, etc.) in First Nations' communities. Provincial and territorial governments need to take immediate responsibility for this. Similarly, they need to step up to the plate in the provision of health care facilities (e.g., hospitals, and upgraded and well-staffed nursing stations). The provinces also need to improve educational systems so that First Nations' youth can enter health care professions on a much larger scale than what is happening at present.

I agree with the authors. The end game is First Nations' self-determination; however, to get there, we need strong partnerships in the provision of higher-quality health care, including a much greater involvement of provincial and territorial governments. The present two-tiered health care system must be discarded. It is racist and that is unacceptable to all Canadians.

\section{Murray Trusler MD MBA}

Queen's University (retired)

Kingston, Ont.

Cite as: CMAJ 2017 September 25;189:

E1217. doi: 10.1503/cmaj.733393

\section{Reference}

1. Katz A, Enns J, Kinew KA. Canada needs a holistic First Nations health strategy. CMAJ 2017;189: E1006-7.

Competing interests: None declared. 